University of Rhode Island

DigitalCommons@URI

Open Access Master's Theses

1976

\title{
An Exploration of the Relationship Between Self-Reported Anxiety and Belief in Internal Versus External Control of Reinforcement
}

Caroline Salvatore

University of Rhode Island

Follow this and additional works at: https://digitalcommons.uri.edu/theses

\section{Recommended Citation}

Salvatore, Caroline, "An Exploration of the Relationship Between Self-Reported Anxiety and Belief in Internal Versus External Control of Reinforcement" (1976). Open Access Master's Theses. Paper 1621. https://digitalcommons.uri.edu/theses/1621

This Thesis is brought to you for free and open access by DigitalCommons@URI. It has been accepted for inclusion in Open Access Master's Theses by an authorized administrator of DigitalCommons@URI. For more information, please contact digitalcommons-group@uri.edu. 


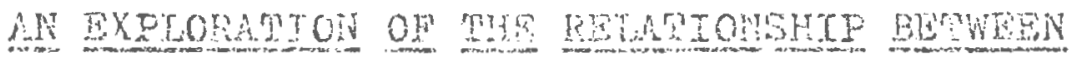

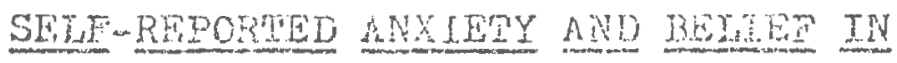

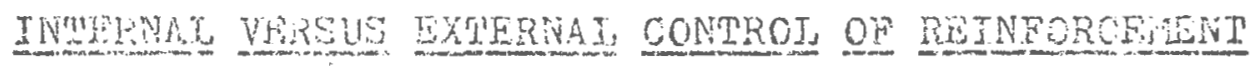

BY

CAROLINE SALVATORE

A THESIS SUBMITTED IN PARTIAL FULFILASANT OF THE REQQUTREMENTS FOR THE DEGREE: OF MASTER OF ARTS

IN

PSYCHOLOGY

UNIVERSTTY OF RHODE ISIAND

1976 


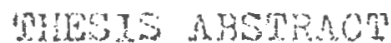

The initial purpose of this study was to explore the reported relationship between subjecijve, debilitating anxiety ard an individual's gereeption that he lacks significant control over life situations.

While much previous research suggests the existence of a positive relationship between anxiety and the variable Fotter has termed external locus of control (LC), these studies have utilized many different measures.

A more refined purpose of the present study thus became the clarification of these constructs through a factor-analytic approach to the following questions: (1) Precisely how are "anxjety" and percejved "locus of control" operationally defined by some of the more widely used instruments?: (2) Are the constructs of anxiety and IC unitary or multidimensional? (3) If there are several components or dimensiors ir the two constructs, do they contribute differentially to a linear relationship?

In the first stage of this research, a 155-item inventory was constructed of 95 anxiety items and 60 LC items drawn from several sources. This instrument was administered to University of Rhode Island undergraduates yielding a sample of 213 subjects. Following principal components analysis (FCA) of the two sets of items respectively, component scores for each subject were generated and a canonical correlation performed. In stage two of the research, 41 anxiety items and $31 \mathrm{LC}$ items were selected on the basis of component loadings of .40 
or higher and lack of significant badings on any other component, A second PCH wes run on each set, and Croribach alpha coefficients of reliability obtained for each scale.

In order to obtain a measure of external reliability for these scales and also to test the stability of the component pattern, a second instrument was compiled consisting of these 70 items. This was adninistered to a new group of U.R.I. undergraduates, yielding a sample of 268 subjects, and readministered to this same group of students four to five weeks later. In all, 202 students participated in both administrations. A single PCA was done on all 70 items combined, with a varimax rotation. Finally, test-retest coefficients and Cronbach alphas were obtained for the three components that most clearly emerged.

By far the strongest and most reliable componert, that emerges is a "general anxiety" component which appears to agree well with Cattell's "O" factor, and indeed contains items from his anxiety scale, as well as the Taylor Manifest Anxiety Scale (TMAS) and the Eysenck neuroticism scale (EPI). While there is evidence for the multidimensionality of Rotter's supposedly unitary I-E scale, the clearest component that emerges is externality, particularly a belief in control by chance or fate. Both the results of the canonical correlation and the single PCA of the 70-item inventory show clear and significant relationships between anxiety and externality on the one hand, and ego strength and internality on the other. 
I would like to extend my deep and warm appreciation to my major professor, Dr. Peter $F$. Merenda, whose unfailing support and guidarce haș sustained the work of this research.

I woujd further like to extend my deep gratitude to Dr. Wayne Velicer for his very patient, extensive, and expert felp rom incejtion to the completion of this work. Further, warm thanks are extended to Dr. Stanley Berger anä Dr. Richard Purnel.I for graciously consenting to act as committee members and for their helpful suggestions and comments.

Finally, I wish to thank Dr. Leila Cain, Dr. Alan Berman, and the graduate assjstants who kindly allowed me access to the undergraduate students in their psychology classes. 
$\underline{\text { Fage }}$

THESIS ABSTRACI . . . . . . . . . . . . i i ACKNOWLEDGRENTS . . . . . . . . . . . . . iv TABLE OF CONTENTS . . . . . . . . . . . . . v I.IST OF TABLES . . . . . . . . . . . . . vi INTRODUCTIOR , . . . . . . . . . . . . . I METHOD .................. . 13 RESUITS . . . . . . . . . . . . 25 DISCUSSION . . . . . . . . . . 53 REFERENCES ................ 57 
MPI-1: Scales, Description of scales, and Number and Source of. Items

MPI-2: Scales, Description of Scales, and Number and source of Items

$3 a$

MPI-l: Arxiety Component one, Preoccupation and Worry

3b MPI-1: Anxiety Component Two, Ego Strength, Confidence, Coping

3d MPI-I: Locus of Control Component one. Control by Fate, Uncertainty About Future

MPI-1: Locus of Control Component "wo;

$3 g$ MPI-1: Description of Components and Exterral Components Four and Five

$4 a$ MPI-2: Component one, General Anxiety

$4 \mathrm{~b}$ MPI-2, Internal-External Items Showing Significant Loadings on the Anxiety Component one

MPI-2, Component Two, Ego Strength, Internality

40. MPI-2, Component Three, Control by Powerful others

4e IPI-2, Components Four, Five and Six, Items, Loadings, Means and Standard Deviations 


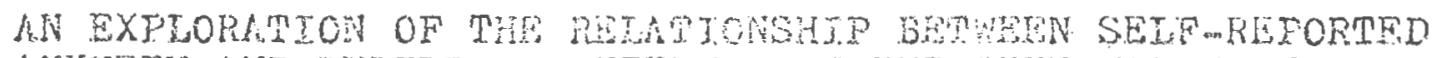
ANYIETY AND BELIAT TN TNTERAST VERSUS EXIERNAL CONTROT OP REINHORCEIUST

The concept that individuals vary in beljeving that important outcomes are contingent upon their owr behavior (internal control) ox independent of it (extexral control) was developed by Julian Rotter (1954. 1972) from social learning theory. Both theory and some highly sugsestive research reviewed, among others, by Joe (1971) imply that an individual's perception that he lacks freedom and ability to control his environment is often associated with increased anxiety and tension.

Several reports in the recent literature have indicated significant positive relationships between various measures of debilitating anxiety and belief in external control.

Butterfield (1964) obtained an $r$ of .61 besween the Alpert-Haber measure of debilitating anxiety and perceived external control (Iiverant scale); and an $r$ of -.81 between the LC scale and the Alpert-Haber measure of facilitating anxiety. The multiple $R$ was .81, an index so high "that it raises a question", writes Butterfield, "about the amount of overlap in the content between the IC and the two anxiety scales. Items in the scales are sufficiently different that one would think they were measuring different variables. However, if further investigations indjcate that the relationship between the scales is as high as this research indicates, then consideration must be given to the possibility that this is tapping the same dimension." 
Subsequent studies have consistently sound sigrificant positive through lower correlations between anxiety and external IC. Feather (1967) obtained an 2 of .38 between external IC and the Alpert-Haber ciebilitating anxiety measure, as well as sjgnjficant positive relationships between externality and neuroticism. Isiberty, Burnstejn and Moulton (1966) obtained an $r$ of .44 between Mandler's measure of fear of failure - the Test Anxiety Questionnaire - and external IC. Tolor and Reznikoff (1967) obtained an $r$ of .31 between a measure of "death anxiety" and IC, Watson (1967), in one of the few studies to focus exclusively on the relationship between anxiety and perceived locus of control, reports an $r$ of .36 between the Taylor Manirest Anxiety Scale (TMAS) and the Rotter I-E (Internal-External) administered to 648 subjects. In a multiple regression study of several variables related to depression published in 1975. Naditch, Gargar and Michael found that one of the highest correlations in the obtained matrix was an $r$ of .31 between Rotter's I-E scale and Cattell's IPAT anxiety scale. Finally, in a small scale study utilizing adult women enrolled in a continuing education program, this writer obtained an $\mathrm{r}$ of .53 for 30 subjects, between the Rotter I-E scale and the TMAS.

While the previous research suggests the existence of a relationship between anxiety of some sort and perceived locus of: control, many different measures have been used, and the lack of conceptual clarity makes it difficult to compare studies. Several problems arise. It would appear 
userul. to determine the anount oî overlap in some of the more commonly-used measures of anxiety. Clarification and refinement of the anxiety construct as it is being operationally defined in various measures is a necessary first step in detexmining the degree of relatjonship between it and externality. In addition to the several usages of the term ("general arxiety" "test anxiety", "death anxiety" facilitating aniety", etc.) some researchers claim that it is a multidimensional construct (Cattell, 1961) while others have treated it as unitary (Eysenck, 1957). The same is true for the most commonly used measures of LC. Rotter (1966) has utilized an unidimensional measure, while factor analytic studies of his instrument by others suggest that it is not. Resolution of tinis prodiem wouià inus isulicate the best wầy to establish the maximum relationship between anxiety and LC. If one or both constructs contain several factors, a multiple regression or canonical correlation approach should bring out the differential contributions of each to a maximum linear relationship.

Finally, there is the problem of the linearity of the relationship. As Joe (1971) notes, "Preceding research has shown linear relationships... as externality increases, so too does anxiety and potential pathology. Although the evidence thus far is not particularly supportive, some have suggested that there might be a curvilinear relationship. That is, either extremely internal or external scores should be associated with pathology. Failure to find such a relationship 
conld be dve to the nature ox the sample groups used or irritations in the measuring instruments."

A djscussion in general theoretical terms of the two constructs under investigation should relp clarify the hypothesized relationship between them,

Anxiety has been varjously cefined. Kubirstein (1975) deseribes s.t as a "subjective sensation similar to fear but less sharply focused." It is, he says, "a state of apprehension or uneasiness concernirg some uncertair event." Regarding its antecedents he states "Often a chronically anxious person is one with a history of stressful experiences that he has not been able to predict or control."

Freud, of course, held that the prototype of all. later anxiety was the "birth trauna" - really a type of massive enviromental assault over which the newborn has no control. Anxiety, then, as Freud conceptualized it, was very intimately related to powerlessness and helplessness, to complete lack of' control over one's environment. It is not difficult to extend this concept and to postulate that when this initial prototypical experience is followed by repeated experiences with a capricious or unresponsive envirorment, the individual learns to leel that his actions have no meaningful effect on the environment; that, in short, he is controlled by it.

It is of passing interest to note that several theorists (Piaget, 1974, decharms, 1968) attribute the development of the abstract concept of causality and of lawrulness in the universe to the child's early attempts at and success with 
causai manipulations of his own erviranment. closejy rejatea to this is the ego prychologist Robert W. White"s (j959) notion of the relationship between ego strength fa factor Cattell ciaineci to be factorially a negative component of axxiety) and competence, the individual's success in being coje to manipulate and to master, to some extent, his own rate. Anxiety, then, wourd seem to contain an element of powerlessness, an inability to predict or control events. linis seems to bear a close and intriguing relationship to the perception of control over one's own destiny versus feeling at the mercy of the environment.

The second variable of interest in this study was designatea by Jujiar Fotter in 1966 as generalized expectancies for interial versus external control of rejnforcement. Again, Rubinstein's (1975) definition of the locus of control variable should bring into clear relief the hypothesized relationship between it and anxiety. He defines it as: "The perceived place from which come the determining forces in one's life. A person who feels he has some control over his fate and tends. to feel more likely to succeed has an internal locus of control. A person with an external locus of control feels that it is outside of himself and therefore his attempts to control his fate are less assured."

Rotter (1966) discusses and defines this personality variable in the broader context of social learning theorys "The effect of reinforcement following some behavior on the part of a human subject is not a simple stamping-in process 
but depends upon whether or not the person perceives a causal relationship between his own behavior and the rewsid. When a reinforcement is perceived by the subject as following some action of his own, but not being entireiy contingent upon his action, then, in our culture, it is typjcally perceived as the result of luck, chance, fate, as under the control of powerful others, or as unpredictable because of the great complexity of the forces surrounding him. When the event is interpreted in this way by an individual we have labelled this a belief in external control. If the person perceives that the event is contingent upon his own behavior or his own relatively permarent characteristics, we have termed thjs a belief in internal control."

While Rotter makes it clear that perceived degree of control may certainly vary in an individual as a function of both specific situation and the value of specific reinforcements for that individual, as a personality variable he views it as a generalized expectancy built up across many life situations, the sum total of which is a general expectation regarding the degree of personal control in the future.

Thus far, these constructs have been discussed in broad theoretical terms. Research results, however, are ultimately based, not on the variables as they are theoretically construed, but in terms of the empirical operations into which they are translated.

The term "anxiety" has several usages in the psychological literature. In particular, the literature distinguishes 
between what is now called transient, situational, or state anxiety, as opposed to a "type of more chronic, pyciniatric, erduring anxiety called trait anxiety: (Mataraca, 1972). It was pointed out earlier that previous studies reporting significant positive relationships between anxiety and perceived external locus of control have utilized a variety of anxiety measures.

Some of the studies have apparently focused on anxiety as a trait - for example, the studies cited earlier by Watson (1967) and Naditch et. al (1975) correlating locus or control with measures of trait anxiety such as the TNAS and cattell's IPAT scale.

Some studies, on the other hand, have focused on the relationship between locus of control and "state anxiety for example, the study by Liberty et. al (1966) which correlated "Test Anxiety" with perceived locus of control. Still others have made further distinctions within the anxiety construct (e.g. debilitating versus facilitating anxiety).

In view of the theoretical discussion of the two constructs given earlier, however, it is hypothesized that a stronger positive relationship should exist between anxiety and externality when anxiety is defined and operationalized as a rather permanent and enduring trait, rather than as a transient, situation-specific or situationally-induced state. For this reason, anxiety in the present research is being defined as a subjective and somewhat chronic sensation of vague distress and "impending doom", a more or less enduring 
bendeney on the part oi an individual toward non-speodic worry and tension. Items to be used in the inverwory constructed for this study have been selected with this distinction in mind, and situation-specific items hive been generally avoided. The sources from which items were drawn are, similarly, trajt measures rather than state measures, defining anxiety in this broader usage of a general predisposition on the part of the individual toward chronic worry and preoccupation.

Just such a model of "general undefended anxiety" has been proposed by Raymond Cattell (1961). Based on years of broad-spectrum factor analytic researches, Cattell has constructed and refined a measure of anxiety which has repeatedly shown a high degree of both internal and external validity. The external validity of the scale rests on agreement with a consensus of psychiatric ratings of anxiety (corrected r's of between .60 and .70); and the very significant differences between the means of anxiety neurotics and the general population means (Buros, 1965). As a second-order factor, Catiell labels it $F(Q)$ II and defines it as "an empirically unitary concept with distinct first-order components whose separate and rather equal contributions make up anxiety."

The five specific first-order components of anxiety have been identified by Cattell as follows: (1) Factor 0 , guilt proneness and general apprehensiveness as characterized in the person who is "moody, a worrier, full of foreboding and 
brocding", (2) Factor c, ego wealkness a measure of paceeived self-effectiveness characterized by inadequacy in meeting life's demands and despair of acting rationally, (3) Factor 24, a measure of "stimulated but undischarged" tension, as charactexized in the person who is "tense, excitable, restless, fretful, impatient...frustrated" (4) Factor Q3, emotional, unconstraint, lack of integration of impulses by will control and stable self-image: the person who is undisciplined, lax, self-indulgent; (5) Factor I, suspiciousness, manifested in the person who "terds to be mistrustful, doubting, selfopinionated, and jealous of others." Cattell notes that some of these factors appear to be contributors to the state of anxiety while others are the result of it.

Because Cattell's concept of anxietyr appears the best approximation to the theoretical meaning discussed herein, and because of the quality and quantity of empirical research which support it, his definition will serve as the guide in the construction of the measure to be used in the present study.

In addition to Cattell's, two other widely-used measures which appear to define anxiety in the same general way will be drawn upon. The Taylor Manifest Anxiety Scale (TMAS) is based on 50 true-false items taken from the Minnesota Multiphasic Personality Inventory (MMPI). The TMAS (Taylor, 1953) correlates about .80 with Cattell's IPAT scale and also measures "free-floating" or "general undefended" anxiety. Unlike the Cattell scale, however, the TMAS items are relatively 
andisguised attempts to meavure the behavioral and physiological conccmitiants of anxiety (a.g. self-reported insomnia, stomach trouble, frequent headaches, weeping, trembling. blushing, etc.) ard to a lesser extent preoccupation with feelings of inferiority, insecurity, guilt, unworthiness, etc. Eysenck's personality Inventory (EPI), the third measure, is based on his factor analytic researches indicating that two broad traits or dimensions of personality are neuroticismstability and extraversion-introversion. Items measuring his neuroticism factor appear to be very similar to the TMAS items except that they are in the form of questions. rather than statements. There also appears to be a good deal of congruence between Eysenck's neuroticism factor and Cattell's anxiety construct. Factor analyses of both the TMA.S (Reynolds and Burdsal, 1975) and the EPI (Velicer, unpublished) reveal several. factors which overlap some of Cattell's five factors. Velicer's change in the format of the EPI from forced-choice to a Likert-type seven-point scale has resulted in revealing the factorial complexity of neuroticism.

The first attempt to measure individual differences in generalized expectancy for internal versus external control was Phares 26-item, Iikert-type scale. This was followed by revisions first by James, then Liverant, Rotter and Seeman. The most widely-used scale at present is Rotter's 29-item forced-choice scale which he regards as basically an unidimensional measure of I-E. The higher the score (the more externaltype items chosen) the more external the subject's perceived 
locus of controj. Subsequeri aralyses by (unir (1969), who a)so added items messuring race relations, Iovenson (1974. 1976) and others have revealed factorial complexity, however, Gurin found factors such as Personal Control, Control Ideology, System Modifiability, and others relevant to race reiations and issues. Levenson found three distinct factors (accounting. however, for only $33 \%$ of the variance): Individual Control, Component "I"; Control by Powerful Others, Component "P"; and Control by Chance or Fate, Componert " $\mathrm{C}$ ".

For the present study, a 155-item instrument was constructed using questions and statements from the sources discussed here.

The 95 items measuring anxiety were assigned to five scales lising items from Each of Gattelu's fivo paotore as "marker" variables. Appropriately similar items from Eysenck's EPI and the TMAS were added to each scale as well. The 60 items measuring perceived locus of control were assigned, again on an ampriori basis, to three scales (Control by Self, Control by Powerful others, and Control by Fate or Chance, respectively) following Levenson's distinctions. Consequentiy. items from Levenson's three scales were used as "marker variables" in the I-E measure. Appropriate items from other sources were also added.

The chief focus of this research, then, is a further clarification and refinement of the reported relationship between anxiety and perceived locus of control. In particular, it addresses the following specific questions; 
(1) What is the nature and extent of tre relationship between IC and anxiety, when the latter is derined and operationalized as a "trait"?

(2) To what extent do three existing measures of anxiety, CatteIl's IFAT anxiety measure, the TMAS, and the Eysenck EPI inventory, overlap - that is, measure the sane thing?

(3) Is anxiety, as a trait, unitary or multidimensional? Eysenck has contended that it is the former, while Cattell holds that it is the latter.

(4) Is the internal-external locus of control construct uridimensional as Rotter has claimed, or multidimensional as Levenson, Gurin and others have found?

(5) If anxiety and I-E contain the several factors or components found by Cattell. Levenson, and others, will these components emerge on relication with a new sample, particularly when a change in format is made from forced-choice to the Iikert-type scale?

(6) If there are distinct components within the anxiety and I-E constructs, will these contribute differentially to a linear relationship between the two? 


\section{METYOD}

subjects

The first 355 -itern inventory was adninistered to a group of University of Rhode Island undexgraduates enrolled in an iritroductory psychology class in the spring of 1976. of these, a hanaful of subjects who faijed to respond to all of the items were discarded, yieiding a final sample of 268 subjects, 69 males and 144 females. All but four of these subjects were between the ages of 18 and 21 . The mean age for the total sample was 19.15 years, with a mean age for the males of 19.45 years and a mean age for the females of 19.02 years.

The secord 70-item inventory was administered to a new group of U.R.I. undergraduates enrolled in an introductory psychology class in the fall of 1976. Ngain, a few subjects were discarded who did not respond to all items, or who did not give an identification number that could be used later for matching purposes on the subsequent re-test. All but six subjects were between 18 and 21 years of age, with a mean for the total sample of 3.9 .57 years.

Four to five weeks later, 202 of this group were available to receive the re-test of the 70-item inventory, 99 males and 103 females.

Attention is drawn to a possible source of bias in these samples. Both the total number of students enrolled in these introductory psychology classes and the proportion of males to females is substantially greater than the sample sizes and 
proportions would indicate. It is possible that the samples nay be more representative of students who regulariy attend class. Note. for example, the loss of 66 students between the test ard re-test of the MPI-2, many of whom vere absent for class on the day of the second administration, which was incidentajly the last day of class for the semester.)

It would also appear that the disproportionate number of females in the samples may indicate a greater likelihood of females atrending class than males.

Since one of the variables being measured in this research was the degree to which a person feels in control of, and resporsible for, his or her life situation, it is possible that these samples were thus biased in the direction of what Rotter has termed internality. In fact, previous research by Rotter and others has concerned itself with the hypothesized positive relationship between academic achievement and internality.

Insiruments

In the first stage of this two-part research, a 155-item instrument was constructed consisting of 95 anxiety items and 60 internal versus external (I-E) locus of control items. The instrument was termed the Multidimensional Personality Inventoiy-1 (MPI-1).

Instrumont \#

Anxiety Items. The 95 items purporting to measure anxiety were drawn from an item pool consisting of three principal 
sources: Catbeli's. IPAT anxiety scales, the Taylor Manifest Anriety Scale (TMSS), and the Eysenck Personalj.ty Inventory (EPT) measuring neuroticism-stabilityr.

Using Cattell's five-factor model of anxiety as a guide, these items were then assigned to scales on an a-priori basis, as follows (a sample item from each scale, along with its source, is given):

Scale $I$, general apprehensiveness and tendency to worry, corresponding to Cattell's 0 factor - 20 items: for example, "I have periods of feeling depressed, miserable, and in low spirits for no sufficient reason" (source IPAT, +).

Scale II, ego weakness, low self-image, or Cattell's cfactor - 20 items: for example, "I shrink from facing a crisis of difficulty" (source TMas, + ).

Scale III, tension, or Cattell's factor Q4 - 20 items: for example, "Would you call yourself tense or highly strung?" (source EPI, +).

Scale IV, emotional control, will control, or Cattell's factor.Q3 - 15 items for example, "When talking I like to get my thoughts organized first rather than say things just as they occur to me" (source: IPAT, + ).

Scale V, suspiciousness or Cattell's factor L - 15 items: for example, "No one would really like to see me in trouble" (source IPAT, -).

The remaining five items all dealt with the supposedly physiological concommitants of anxiety, sweating, trembling, stomach trouble, shortness of breath, frequent headaches, and 
were placed in a sixth scale the author terned hypochrondriasis. An exact breakdown of the sources of each item for each scale is given in Table 1 . In the tota? 95-item anxiety inventory, 13 items came from the EPI. 24 items from the IMAS, and 58 itoms from the Catteli IPAI inventoly; (The parent instrument for the IPAT is the 16-PF personality inventory of Cattell's, and the parent instrument por the TMAS is the MMPI.)

Some items were worded in a positive direction (indicated in the examples given by a "+" following the source of the item); that is, a tendency to agree strongly to such items would give the subject a high score on the scale as defined; and some items were worded in a negative direction (-); that is, a tendency to agree strongly would give the subject a low score on the scals as defined.

Locus of Control or Internal-External (I-E) Items. AIthough the 60 items purporting to measure an individual's perceived locus of control were also drawn from several sources, a breakdown by source has not been given. The reason for this is that the sources themselves tended to use the same or very similar items varying the number of items or the format, rather than the items themselves. The most widely-used I-E measure at present is Rotter's unidimensional I-E scale of 29 pairs of forced-choice items, scored in the direction of externality. Most of the current scales for measuring I-E in adults appear to dexive from earlier work by James and Rotter (I966). 
MPI I Scales, Deseription of Scajes, and Number ard source of Items

\section{ANXIETI SCAIES*}

Scale Description

I Genexal apprehensiveness,

tendency to worry.

Catteli's O ractor

II Ego weakress, poor self-

confidence and image,

Cattell's factor C-

III Tension, Cattell's

factor Q4.

IV Emotional control,

Catteli's factor 83

$\mathrm{V}$ Suspiciousness,

Cattell's factor I

TOTAL
Source: EPI TMAS

IPAT Total

$\begin{array}{llll}8 & 5 & 7 & 20\end{array}$

$54 \quad 11$

20

$\begin{array}{llll}0.5 & 10 & 15\end{array}$

$\begin{array}{llll}0 & 0 & 15 & 15\end{array}$

$\begin{array}{llll}0 & 0 & 15 & 15\end{array}$

$13 \quad 29 \quad 58 \quad 90$

\section{LOCUS OF CONMROL}

Scale Description Source:

I Individual locus of control, Levenson's I factor

II Belief in control by $\begin{array}{lll}0 & 20 & 0\end{array}$ 20 others, Levenson's $P$ factor

III Belief in control by $0 \quad 020$ 20 chance or fate, Levenson's C factor TOTAI $20 \quad 20 \quad 20$ 60

*Five items comprising an "hypochonoriasis" scale were added to the 90 anxiety items. These items were drawn from the TMAS and the EPI. 
Subsequentiy, Rotiter's $I-E$ scale was factor analyzed by Gurin (1969), Levenson (1.974, 2976), and others. Levenson modified the format, using a Iikertwtype scale. Both Gurin and Levenson found the I-E construct to be multidimensjonal. In particular, Ievenson found three distinct components, which she has subsequently termed "I" "P", and "C" factors control by the individual, control. by "powerful others", and control by fate or chance, respectively. Gurin suggests, in addition, a distinctior within the "I" or internality component between personal control and what she terms "control ideology".

The Levenson model was followed in the present study。 yielding three scales, with 20 items each. In constructing the "I" scale, however, some items were worded in the first person and some items were worded in the third person and designed to "pull out" a more general ideology factor, following Gurin's distinction.

The scales and a sample item from each scale follow:

Scale I, belief in personal control, or Levenson's "I" factor - 20 items: for example, "Concerning man's freedom to make his own choices, I believe man is mostly free to do so" (control ideology, + ).

"My life is determined by my own actions" (personal control, + ).

Scale II, belief in control by powerful others, or Levenson's "P" factor - 20 items for example, "It's not what you know, but who you know that counts" (powerful others, + ). 
Scale III, control by chance or fate, Levenson "s "C" factor = 20 items: for example, "l'o a great extent my life is controlled by accidental happenings" $(t)$.

Most of the 60 I-E items were. worded in the first person: all of the items witinin a particular scale were worded in the same direction: that is, a tendency to agree with such items yields a high score on the scale as defined.

Format of the 155-Item Inventory. With the exception of 13 EPI items which were in the form of questions, all of the items were statements. AlI items were responded to on a fivepoint scale, with the subject indicating his degree of agreement ox disagreement to each item on a detachable answer sheet. The 155 itoms were somewhat randomly ordered, and the answer scale was as follows:

5. Very frequently or almost always TRUE

4. Frequently or TRUE most of the time

3. Occasionally or TRUE "now and then"

2. Rarely or true "once in a great while"

1. Very rarely or almost never true

Thus, scores on the total inventory could range theoretically from 155 to 775. Any subject who did not respond to all the items was discarded.

\section{Instrument $\# 2$, MPI-2:}

The scores of the 213 subjects who took the first inventory were factor analyzed in two principal componentianalyses, type PAl, with varimax rotations, first for the anxiety items, and 
then for the I.E items. A second study was then urdertaken based on these results.

A second instrument (MPI-2) was constructed, consisting of three anxiety scales.with a total of 40 items, and three I-E scales with a total of 30 items. For the most part, the criteria for selection of an item was that in the PCA it had a component loading of .40 or greater and did not load significantly on any other component. An occasional item with a component loading of . 31 or greater but less than .40 was used, if necessary, to provide sufficient number of items for each scale. Of the 70 items selected, only five such items (component loadings less than .40) were used. Complex items (items showing significant. loadings on more than one component) were avoided altogether.

The resulting scales with a sample item.for each follows! Anxiety Scale I, tendency to preoccupation and worry 18 items with component loadings between .42 and .73. "I fiind myself thinking over trivial troubles again and again, and have to make a real effort to put them out of my mind" (source: IPAT; PCA loading .73).

Anxiety Scale II, "ego strength" - 10 items, loadings ranging from . 40 to . 56: "I feel ready for life and its demands" (source: IPAT; loading on PCA.56).

Anxiety Scale III, emotional control and calmness 12 items with loadings from -.31 to .59: "I like to wait till I am sure what I am saying is correct before putting forth an argument" (source, IPAT, .59). 
I-E Scaie I, control by fate or chance - 10 items with leadings between .48 and .658 "Iro a great extent my life is controlled by accidental happenirgs" (sources C scale: 65).

I-E Scale II, contiol by self $\ldots$ items with loadings between. 31 and .59: "In regard to my own life I generally feel more hoperul about the future than not" (sources "I" scaje: .59).

I-E Scale III, control by powerful others - 10 items with loadings between .35 and .67 : "Getting what I want requires pleasing those people who are above me" (source: "P" sca.le; .67).

Format of the MPI-2. The same format was followed as in the IPIm 1. Subjects responded on a five-noint scaje. Changes were made only to ensure that all items within a particular. scale were worded in the direction of the scale as defined. The exception was Anxiety Scale III, which contained five items worded positively (emotional control) and five items worded negatively (emotional tension and lack of control), but these five items were subsequently reflected when the data cards for each subject were punched. Hence, the scores of each subject on this scale can all be interpreted as reflecting the degree of emotional control and lack of tension. Table 2 gives the breakdown of items in each of the six scales of MPI-2, according to the number and source of each item in the scale. 
MPI.-2 Scales, Deseription of Scales, and Number and source of Items

\section{ANXIETY SCALES}

\begin{tabular}{|c|c|c|c|c|c|}
\hline Scale & Description & Source: EPI & TMAS & IPAT & Total \\
\hline$I$ & $\begin{array}{l}\text { Tendency to worry and } \\
\text { preoccupation with } \\
\text { self }\end{array}$ & 3 & 7 & 8 & 18 \\
\hline II & $\begin{array}{l}\text { Confidence, ego } \\
\text { strengti, coping }\end{array}$ & 0 & 1 & 9 & 10 \\
\hline \multirow[t]{2}{*}{ IXI } & $\begin{array}{l}\text { Relaxed, calm, } \\
\text { lacks tension }\end{array}$ & 2 & 4 & 6 & 12 \\
\hline & TOTAL & 5 & 12 & 23 & 40 \\
\hline
\end{tabular}

\section{I-E SCALES}

\begin{tabular}{|c|c|c|c|c|c|}
\hline Scale & Description & Source: I & $\underline{P}$ & $\mathrm{C}$ & Total \\
\hline$I$ & $\begin{array}{l}\text { Control by self, } \\
\text { optimistic personal } \\
\text { control. }\end{array}$ & 10 & 0 & 0 & 10 \\
\hline$I I$ & $\begin{array}{l}\text { Control by fate, } \\
\text { uncertainty about } \\
\text { future }\end{array}$ & 0 & 0 & 10 & 10 \\
\hline III & $\begin{array}{l}\text { Powerlessness, } \\
\text { attribution of power } \\
\text { to others }\end{array}$ & 0 & 10 & 0 & 10 \\
\hline & TOTAI & 10 & 10 & 10 & 30 \\
\hline
\end{tabular}




\section{Procedure}

In the first part of this study, undergraduate students enrolled in an introductory psychology class were administered the 1.55-item MFI-1 during a 50-minute lecture period premempted for this purpose. Scores of 213 subjects on the 95 anxiety items were subnitted to principal components analysis (PAI) using a varimax rotation. The $60 \mathrm{I}-\mathrm{E}$ items were also analyzed using a PCA with varimax rotation.

Component scores for each subject were then generated and a canonical correlation between the seven arxiety sca?es and the five I-E scales resulting from the princjpal conconents aralyses, was perforined.

From these initiai results, 41 anxiety items and 31 Im items were selected which had the highest component loadings on their respective components and insignificart loadings on any other component. These two sets of items were then submitted, respectively, to a second principal components analysis.

The Cronbach alpha coefficients for the five anxiety scales and five I-E scales thus generated were obtained.

Based on the results of the second principal components analyses and the obtained alpha coefficients of internal scale reliabilities, a second instrument, the MPI-2, was constructed. The second phase of this study was then initiated.

The MPI -2 instrument of three anxiety scales ( 40 items) and three I-E scales (30 items) was then administered to a 


\section{$-24 \ldots$}

group of subjects during recitation sections of their introductory psychology class, yielding a new sample of 268 subjects. Four to five weeks later, 202 of these same subjects participated in a re-test of the WPI-2.

The scores of the 268 subjects on the 70-item MPI-2 were ractor analyzed using FCA with an oxthogonal rotated solution. froworos of the 202 subjects who were available for the re-test administration four to five weeks later were also submitted to PCA, as a check on the reliability of the obtaired component pattem.)

The 202 test-re-test scores were then used to obtain the Pearson $r$ coefficient of external reliability for the 70-item test as a whole, and for each of the three components which clearly emerged in the final results. Cronbach alpha coefficients were also obtained for each of these three scales. 


\section{RESUYRS}

MPI-1

The first study in this two-part research focused on the results of the administration of MPI.-l to the sample of 213 subjects.

Principal components analysis with varimax rotation was performed on the 95 anxiety items, and seven components were extracted, accounting for $37.1 \%$. of the variance.

These components were extracted in a principal components analysis program innovated by Velicer (1975) which extracts " $m$ ". number of components from the set of " $p$ " observed variables, utilizing his "stopping rule"; that is, a matrix of partial correlations is employed and "no components are extracted after the average squared partial correlation reaches a minimum."

By far the strongest component to emerge corresponds very well to Cattell's 0 , although containing items from all of the original six anxiety scales, and accounted for $18 \%$ of the variance. Fifty-three items showed loadings on this component of between . 30 and .?3, though some of these items showed weaker but significant loadings on other components as well. All 53 items showed strong logical consistency, concerning preoccupation with feelings of worry, guilt, worthlessness and insecurity.

The other six components to emerge were much weaker, accounting for between $2.5 \%$ and $4.6 \%$ of the variance. Though weakly corresponding to Cattell's five factors in the original model, many items had low loadings (between .30 and .35) and 
were complex, showing much overlap in the components of ego strength, tensior, emotichaj control, and nypochondriasis. The single exception was component seven, an excellent approximation to Cattell's orjginal "suspiciousress", or I scale. Although only accounting for 2.5\% of the variance, the 12 items loading on this component contained seven of Catteli's I items, and also showed great logical consistency. Eight of the 12 items contained the word "people" used in a negative (hostile ox suspicious) context.

Principal components analysis of the 60 I-E items with varimax rotation extracted five components, accounting for $34.8 \%$ of the variance.

Again, Velicer's (1976) stopping rule was employed in determining the " $m$ " number of common components for " $p$ " observed variables. In the case of the 60 I-E items, then, five components were extracted before the average squared partial correlation reached a minimum.

It will be recalled that in the original construction of the anxiety measure, six scales were employed on an a-priori basis. Similarly, in the construction of the I-E measure, three scales were employed. The fact that more components than scales were extracted using Velicer's method seems to indicate the greater sensitivity of a Iikert-type format in revealing factorial or component complexity.

By far the strongest component to. emerge in the I-E measure was the "control by chance" or Levenson's "C" component. The 29 items with loadings between .31 and .65 on this component 
accounted for $17.4 \%$ of the variance - 3.8 times originally from the "C" scale, nine from the "P" scale, and two (with negative loadings) were from the "I" scale.

The second component, control by powerful others, accounted for $6.6 \%$ of the variance and contained 12 items with loadinge between . 32 and .67 - II of these were "p" items in the original scales and one was a "C" item.

The remaining three components appear to be variants of the "I" scale, concerning personal control, personal responsibility, and a sense of optimistic coping with life. The possibility mentioned earlier that extreme "I" scores could be related to pathology (Joe, 1971) received a weak possibility of support in I-E component 5. This component contained eight items, five of which were very strongly worded "I" items. Although only accounting for $3.4 \%$ of the variance, the eight items in total context suggest the possibility of an extreme, tough-minded independence with anti-social aggressiveness, aloofness.

The results of the first $\mathrm{PCA}$ - the seven anxiety components and five I-E components along with their items and item loadings - are presented in Tables $3 \mathrm{a}$ through $3 \mathrm{~h}$. Note that the three anxiety components and their respective items, and the three I-E components with their respective items, were those which subsequently constituted the second 70-item, sixscale instrument, MPI-2. 
Caronical Correlation

Component scores for the 21.3 subjects were generated for all 155 items, and a canonical correlation was performed between the seven anxiety scales and the five I-E scales. Four significant canonical correlates wexe extracted, only one of which, however, is clearly interpretable. It is possible that having items within comporents worded in both positive and negative directions affected the results, and particularly the signs, of the caronical variable loadings, tinus leading to contradictory results for some of these canonical correlations. Consequentiy, only one canonical correlation will be interpreted. The first canonical $r$ equaled .75, extremely significant, and showed that a linear combination on the anxiety variabie of ego strength (canonical variable loading.71) and low general anxiety (variable loading -.53) is most strongly associated with a linear combination of an internal locus of control (variable loading .69) and low Delief in control by chance or fate $(-.53)$. Since items in these four scales were for the most part worded in a direction consistent with the scale name, and since this finding is logically consistent, it appears legitimate.

(A second weighted linear combination of anxiety variables with I-I variables showed a highly significant canonical correlation of .69 , but contained contradictory combinations. only two of which make sense. High anxiety in the first set loaded .46 with a belief in control by chance in the second set, loading .57). 


\section{TABLE $3 a$}

MPI-I: Anxiety Component one, Prenccupation and Worry $k=18$

Items and Item Loadings

Item

Item

Loading

1.

20

I frequently notice that my hands

.42

shake when I try to do something.

2

6

Are you often troubled by feelings

.56 of guilt?

In the midst of social groups I am revertheless sometimes overcome by feelings of loneliness and worthlessness.

4

48

I worry quite a bit over possible misfortunes.

5

54

I have difficulty falling asleep

at night through worrying over possible misfortunes.

6

35

Do you often worry about things you .64 should not have said or done?

Some people seem to ignore or avoid .48 me although I don't know why.

I feel restless often as if I want something but I do not know what.

I have a great deal of stomach trouble.

I find myself thinking over trivial troubles again and again and have to make a real effort to put them out of my mind.

$11 \quad 14$

Do you worry about awful things that might happen?

I have periods of feeling depressed, .65 miserabje and in low spirits for no sufficient reason. 


\section{TAs: $3 \mathrm{a}(\mathrm{con}$ inued)}

Item if

Ttem

Loading

1.37

I am usially self-conscious. $\quad .46$

14.66

I find trat my feelings tend

.49 to "boil up" inside me.

1543

I sometimes feel that I am .68 about to go to pjeces.

$16 \quad 27$

I have scmetimes felt that djfficulties were piling up so high that I could not overcome them.

$17 \quad 21$

I am troubled by feelings of .68 gujit or remorse over quite small matters.

$18 \quad 34$

I feel anxiety about something .62 or someone almost all of the time. 
MPI-1: Snxiety Component Two, Ego strength, confidence, Coping

Items and item Loadings

In my personal life I reach the goals I set most of the time.

20

29

However difficult and unpleasant

the obstacles, I persist ard stick to my original intentions.

$21 \quad 25$

I am usually able to find enough energy to face my difficulties.

I make it a point not to be absentminded or forgetful of details.

I would prefer to lead the same kind of iife I do now ratinew inan a more sheltered life with less difficulties to face.

24

22

I an aware of having some character. .40 istics in which I feel superior to most people.

$25 \quad 49$

In a strange city I would feel pretty free to walk around wherever I liked.

$\begin{array}{lll}26 & 61 & \text { I do not tire quickly. } \\ 27 & 8 & \begin{array}{l}\text { I feel ready for life and its } \\ \text { demands. }\end{array}\end{array}$
generally keep up hope. 


\section{TALTE 30}

MPI-I: Anxiety Component Three, Emotional. Control, Caimness, Lack of Tension $k=12$

than say things just as they occur to me.

I am usually able to keep from blurting out remarks that hurt people's feelings. way you move? without being bothered by people making a lot of noise around me.

In going places, eating, working, etc., I go about in a calm, deliberate way rather than rush from one thing to another.

I am usually calm and not easily upset.

it to myself rather than need to let off steam.

I have periods of such great rest- -.34 lessness that I cannot sit long in a chair (reflected).

When something really upsets me, I .44 generally calm down quickly. 
THBTE 30

MPI-1. Locus; of Control Component owe, control by Fate. Uncertainty About Fiture $k=10$

\section{Items and Itern Loadings}

\begin{tabular}{|c|c|c|c|}
\hline$I$ & 10 & $\begin{array}{l}\text { I think that life is mostily a } \\
\text { gamble. }\end{array}$ & .48 \\
\hline 2 & 24 & $\begin{array}{l}\text { I feel that most people could be } \\
\text { described as victims of circum- } \\
\text { stances beyond their control. }\end{array}$ & .55 \\
\hline 3 & 17 & $\begin{array}{l}\text { To a great extent, my life is } \\
\text { controlled by accidental } \\
\text { happenings. }\end{array}$ & .65 \\
\hline 4 & 51 & $\begin{array}{l}\text { When I get what I want it's } \\
\text { usually because I'm lucky. }\end{array}$ & .61 \\
\hline 5 & 63 & $\begin{array}{l}\text { Many times I might just as well } \\
\text { decide what to do by flipping a } \\
\text { coin. }\end{array}$ & .60 \\
\hline 6 & 57 & $\begin{array}{l}\text { Wost of the frustrations and } \\
\text { difficulties I have encountered } \\
\text { in my life are due to circum- } \\
\text { stances beyond my control. }\end{array}$ & .50 \\
\hline 7 & 38 & $\begin{array}{l}\text { I have often found that what is } \\
\text { going to happen. will happen. }\end{array}$ & .40 \\
\hline 8 & 45 & Life is too full of uncertainties. & .58 \\
\hline 9 & 31 & $\begin{array}{l}\text { A person cannot really be the } \\
\text { master of his or her own fate. }\end{array}$ & .46 \\
\hline 10 & 2 & $\begin{array}{l}\text { Much of the time the future seems } \\
\text { uncertain to me. }\end{array}$ & .59 \\
\hline
\end{tabular}




\section{PABIE $30^{\circ}$}

MPI--1. Locus of Control Component Two,

Control by Self, Optimistic Coping

$$
\mathrm{k}=10
$$

Items and $I t \in m$ Loadings

I am usualiy able to protect my personal interests.

1325

In regard to my own lire. I generally feel more hopeful e.bout

the future than not.

14

64

When I make plans I am almost certain to make them work.

Concerning man's freedom to make

his own choices, I believe that man is mostly free to do so.

Who "gets to be boss" depends mostly .58 on who has skill and ability.

1711 There is a direct connection between .52 how hard I study and the grades I get.

$18.52 \quad$ pily life is mostly in my own hands .57 and $I$ am in control of it.

What I will be doing ten years from .42 now depends to a great deal on choices that I make now. 


\section{THSBE 3N}

MPI-1: Locus of Control Component Three,

control by othere, powerlessness $\mathrm{k}=10$

Items and Item Lo adings

Item \#

Item

Loading $21 \quad 26$ Many times the reactions of other .52

hazard to me.

22

40 Getting what I want requires

pleasing those people who are

above me.

$23 \quad 19$

Even with good ability I will not

.60

be given a position of responsibility

without help from those in power.

24

32

In order to make my plans work, I

.60

make sure they fit in with the

desires of people who have influence.

25

33

Good grades in school depends mostly .55 on whether or not the instructor

likes me.

$26 \quad 47$

It's not what you know but who you know that counts.

$27 \quad 59$

9 People like myself have very little .44

9 People like myself have very little .44 chance of protecting our peisonal interests when they conflict with those of people in power.

$28 \% 65$ My life is chiefly controlled by other people.

$29 \quad 3$

The actions of other people towards

.44

$30 \cdots 53$

I feel that my getting a good job

depends mostly on knowing the right people. 


\section{TABSe $3 \mathrm{~s}$}

MPI-I, Description of Compenents and Sample Items from Each for Anxigty Components Fovr Five, Six and Seven

\section{Anxiety Component four:}

Coping with life in a calin, active persevering way.

\begin{tabular}{llc} 
Item \# & Item & Loading \\
\hline 74 & $\begin{array}{l}\text { In a strange city I would ieel pretty } \\
\text { free to waik around wherever I Iiked. }\end{array}$ & .56 \\
57 & I do not tire quickly. & .52 \\
63 & $\begin{array}{l}\text { I shrink from facing a crisis of } \\
\text { difficulty. }\end{array}$ & -.42
\end{tabular}

Self-pitying, preoccupation with self, hypochondriasis

\begin{tabular}{clc} 
Itam $\#$ & Item & Loading \\
\hline 34 & $\begin{array}{l}\text { No one would really like to see me in } \\
\text { trouble. }\end{array}$ & -.55 \\
37 & I have very few headaches. & -.47 \\
108 & Do you suffer from sleeplessness? & .45 \\
\hline
\end{tabular}




\section{AEDS 36 (continued)}

Anxiety Component Six:

Emotionzl restraint, relaxed, easy-going, calm

\begin{tabular}{|c|c|c|}
\hline Item \# & Iten & Loading \\
\hline 27 & $\begin{array}{l}\text { I an usually calm and not easily } \\
\text { upset. }\end{array}$ & .60 \\
\hline 96 & Are you an irritable person? & -.46 \\
\hline 14$]$ & $\begin{array}{l}\text { If someone annoys me I can keep i.t to } \\
\text { myself rather than need to let off } \\
\text { steam. }\end{array}$ & .46 \\
\hline
\end{tabular}

Arxiety Component Seven:

Suspicious, hostile, negative toward others

Item \# Item Loading

116 I tend to he critical of other ‥ people's work.

128 When people shout at you, do you .42 shout back?

100 It is mainly the fear of being caught .41 that keeps most people honest.

2 I am aware of having some characteris- $\quad .40$ tics in which I feel superior to most people. 
MPI-1: Description of Components and Sample Items from Each for Internal-External Components four and Five

31 My life is in my own hands and I am in .57 control of it.

69 What happens to me is my own doing. .56

104 My lif'e is chiefly controlled by other -.44 people.

118 My life is determined by my own actions. .55

$.72 \ldots$ I can't understand how it is possible to .42

133 When I get what I want it's because I worked for it. 
whe "best" 4. anxiety ktems (that is, items with significant component loadings and jusignificant loadings on other components) were then resubmitted to PCA, varimax rotation, and five componerts were extracted accounting for $39.4 \%$ of the variance. (This time, however, the number of comporents to be extracted was speciried beforehand by the researcher.) The same procedure was corried out with 3]. I-E items, and three components were extracted, accounting for $35 \%$ of the variance.

Cronbach alphas (a measure of the internal consistercy of the scales) were then computed.

of the anxiety scales, only the first scale, with all of the items worded in a consistent direction, yielded a satisfactory alpha coefficient of .91. Nll of the other scales showed unsatisfactory internal reliabilities of between .16 and .42 , although it is felt that this could have been due in part to having items within these scales that were worded in both positive and negative directions. Reliabilities (internal consistencies) for the three I-E scales fell between .80 and .20 , with the control by fate scale showing the highest internal consistency, alpha $=.80$, followed by scale three, control by powerful others, with an alpha coefficient of .67 . It would appear, then, that only the $C$ and $P$ scales have minimally satisfactory internal reliabilities. Based on these results, three anxiety scales and three I-E scales were retained with a total of 70 items. 
$M P Y-2$

In the second part of this two-stage research, a new instrument, mPI-2, was constructed.

The second instrument consisted of 40 anxiety items placed ir three scales as foliows: "General Preoccupation and Worxy" - 18 items; "Ego Strength and Coping" - 10 items; and "Emotional Control" - 12 items. These items and their loadings on the original PCA were given in Tables $3 a$ through $3 c$.

The I-E scales in the second instrument (MPI-2) consisted of three scales as follaws: "Control by Fate" - 10 items: "Control by Self" - 1.0 items; and "Control by Others" - 10 items. Refer back to Tabies $3 d$ through $3 f$ for these items and their loadings in the first principal components analysis.

The second instrument consisting of 40 anxiety items and 30 I-E items was administered to U.R.I. undergraduates, yielding a sample of 268 subjects.

It was decided to analyze all 70 items in a single PCA. (type PAl, varimax rotation). With six components extracted, 34.5\% of the total variance was accounted for. Although this is lower than might have been expected, a much clearer component pattern did emerge - with substantially higher loadings of these items on their respective components and quite a few items showing loadings as low as .00 on other components.

Again, the strongest component to emerge was the "general anxiety" component, accounting for $16.7 \%$ of the variance. Fourteen items showed loadings on this component between .52 and .72, with insignificant loadings on any other component. 
These items agein wore higrny consistent and all concorned an individual's tendency toward worry and preocewpation with negative feelings. The item with the highest loading on this component is typical: "I find myself thinkjng over trivial troubles again and again and have to make a real effort to put them out of my mind." All 14 items in fact contained eithex a vaxiant of the word "feeling" (in a negative context) or the words "worry" or "trouble". Three of these items came originally from Eysenck's EPI inventory, four from TMAS, and sever froin Cattell's IPAT anxiety scales. These items, their component loadings, means, and standard deviations are given in Table $4 a$.

In the light of the original proposition that anxiety is positively related to an individulal's perception that ho lacks clear control over his own life, it is interesting to note that eight items reflecting this perception also loaded on the arxiety component one. Seven of these items were originally from the I-E scales of control by chance and control by powerful others. For example, the item "My life is chiefly controlled by other people" (an item from the "p" scale of the I-E variable) loaded . 46 on the anxiety component, and the item "Much of the time the future seems uncertain to me" (originally a "C" item in the I-E scales) loaded .44. These icems, their component loadings, means and standard deviations axe given in Table $4 b$.

The second component to emerge, also interesting in the light of the original proposition, appears to be a combination 


$$
-42 \div
$$

of the "ego strength" and internality scales. This component accounted for $4.8 \%$ of the variance and contaired seven items with loadings between .50 and .61 . These items are also consistent with an individual's positive, confident attitude toward self and one's future. For example, the I-E item "When I make plans I am almost certain to make them work" Ioaded.6i on this component; and an item originally from Catte.II's ego strength scale C+ "I am usually able to find enough energy to face my difficulties" loaded .50. The seven items showing substantial loadings on this component are given in Table $4 \mathrm{c}$.

The third component clearly corresponded to what Levenson has termed "Control by Powerful Others". The five items which clearly loaded on this component (from between $4: 3$ to .65) were in fact all items originally drawn from the "p" scale; for example, "Getting what I want requires pleasing those who are above me."

The fourth component contained four clearly good items, reflecting a subject's degree of emotional control and calmness - all four items originally from Cattell's Q3 and Q4 scaies.

The fifth component with five signifisant items clearly corresponds to the "Control by Chance or Fate" scale of the I-E variable.

The sixth and final component had only three geod items, which appear to measure the degree of personal responsibility an individual feels. 
Items, component loadings, means and standard deviations for component three are given in lable $4 d$. Components four, five, and six, containing as they do relatively few good items, have been combiried in Table $4 \mathrm{e}$.

In a final step. Pearson product-moment coefficients of external reliability were complited for the 202 subjects who participated in a iest-re-test of the MPI-2. In addition, a second PCA of the total 70-item inventory was performed, as a test of the reliability of the component pattern. (As was expected, the component pattern remained fairly stable. The amount of variance went up somewhat to $38.9 \%$, and although the component loadings of some items shifted somewhat overall to higher loadings, almost all of the same items loaded on the same components.)

Cronbach alpha coefficients, as a check on the internal reliabilities of the three strongest components, were also computed. The test-re-test coefficients and the cronbach alphas are reported in Table 5.

For component one, the general anxiety component consisting of 24 items, the test-re-test coefficient was .77; the Cronbach alpha was .90 . Tor component two, consisting of seven items measuring "ego strength", the test-re-test coefficient was .52, and the Cronbach alpha was .69. For the third component, five items measuring control by powerful others, the test-re-test coefficient was .64 , and the alpha coefficient was .7I. 
ThSIS the

MPI-2, Component Une, General Anxiety

Items, Loadings, Means ard Stzndard Deviations

$$
k=14
$$

Item

Loading

$\bar{Y} \quad$ S.D.

I find myself thinking over trivial

$\begin{array}{lll}.72 & 2.51 \quad .87\end{array}$

troubles again and again and have

to make a real effort to put thein

out of my mind.

(Highest loading on other factors .14)

Do you often worry about things you

$.71 \quad 2.88 \quad 1.04$

should not have said or dore?

(Highest loading on other factors .12)

I sometimes feel that I am about to

$.66 \quad 2.03 \quad 1.00$

go to pieces.

(Highest loading on other factors .23)

I have periods of feeling depressed, $\quad \begin{array}{llll}.66 & 2.45 & 1.10\end{array}$ miserable and ir low spirits fior.

no sufficient reason.

(Highest loading on other factors .25)

I am troubled by feelings of guilt or $\begin{array}{llll}.65 & 2.11 & 1.11\end{array}$ remorse over quite snall matters.

(Highest loading on other factors .17)

In the midst of social groups I am $\quad .62 \quad 2.54 \quad 1.01$ nevertheless sometimes overcome with feelings of loneliness and worthlessness. (Highest loading on other factors .10)

I. find that my feelings often tend to $.63 \quad 2.85 \quad 1.15$ "boil up inside me".

(Highest loading on other factors .18)

I feel restless often, as if I want

$.59 \quad 3.13 \quad 1.07$ something but I do not know what.

(Highest loading on other factors .20)

I have sometimes felt that difficulties $.58 \quad 2.62 \quad 1.04$ were piling up so high that I could not overcome them. (Highest loading on other factors .16) 


\section{MABE}

Itein

Loading $\bar{X}$ S.D.

I feel anxiety about something or .58 $2.52 \quad 1.14$ someone almost all the time.

(Hjghest loading on other factors .12)

Do you often worry about awful things $.44 \quad 2.44 \quad 1.09$ that might happen?

(Highest loading on other factors .17)

I worry quite a bit over possible

.57

2.30

.93 misfortunes.

(Highest loading on other factors .23)

I have dificulty falling asleep

$.57 \quad 1.85 \quad .92$

at night through worrying over

possible misfortunes.

(Highest loading on other factors .21)

$\begin{array}{llll}\text { Are you often troubled by feelings of } & .55 & 2.55 & 1.05\end{array}$ guilt?

(Highest loading on other factors .15) 
MPI-2, I-E Items Shoving Sjgnificant Loadings on the Arxiety component one

Items and Iroadings on Anxiety, $P$ and $C$ Components $k=8$

\section{Item}

Wuhpor the lime the future

$$
\text { Loadings on }
$$

seems uncertain to me.

The actions of other people

towards me ofien leave rie

baffied.

To a great extent my life is

controlied by accidental

Anxjety "P" "C"

happenings.

Many times the reactions of other

.38

$.06 \quad .22$

.44

.43

$.07 \quad .24$

people seem hap-hazard and puzzling

$\begin{array}{lll}.39 & -.09 \quad .43\end{array}$

to me:

Iife is too full of uncertainties. $\quad .41 \quad 0.25 \quad .34$

Mary times I might just as well

$.32 \quad .02 \quad .24$

decide what to do by flipping

a coin.

My life is chiefly controlled by

other people.

Some people seem to ignore or

avoid me although I don't

know why.

$.46 \quad .26 \quad .20$

$.39 \quad .09 \quad .02$

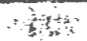


MPI-2: Component: Two, So Sirength, Internality

Items, Lnadings, Neans and Standard Deviations $k=?$

\section{Itrein}

Loading

$\overline{\mathrm{X}}$ S.D.

When I make plans I am almost

$.61 \quad 3.70 \quad .78$
certain to make them work.

(Highest loading on other factors .14)

Concerning man's freedom to make his

$.57 \quad 2.67$

.96

own choices, I believe a person is mostly free to ào so.

(Highest loading with other factors .18)

My life is in my own hands and I am in $\quad .57 \quad 3.84 \quad .89$ control of it.

(Highest Ioading on other factors .28)

I am usually able to protect my own $\quad .51 \quad 3.82 \quad .80$ nersonal interests.

(Highest loading on other ractors .11)

I am usually able to find enough energy $\quad .50 \quad 4.11 \quad .76$ to face my difficulties.

(Highest loading on other factors .24)

I am aware of having some characteris-

$.50 \quad 3.20$

.99

tics in which I feel superior to most

people.

(Highest loading on other factors .22)

In regards to my own life I generally

$.50 \quad 4.10$

.83

feel more hopeful about the future

than not. 


\section{TABIE 40 (continued)}

\section{other Itens Ioadine Sigrifjeanty Eut Not Simply}

Item

Loading

In my persona? life I reach the goals I set

.35

most of the time.

However difficult and unpleasant the obstacles,

I persist and stick to my original intertions.

.33

In ordinary difficulties I usually keep up hope. .46

In a strange city I would feel pretty confident .46

about walking around wherever I liked.

I feel ready for life and its demands.

.56

I do not tire quickly.

.34 
MPI-2: Corponent mone, Control by powerful others

rtems, Loarlings, Means anci Standard Deviations $k=5$

\section{Item}

Ioadings $\bar{X}$ S.D.

I feel that my getting a good job depends on knowing the right

$\begin{array}{lll}.65 & 2.86 & .97\end{array}$
people.

It's not what you know but who you know that colints.

$.65 \quad 2.93 \quad .98$

Getting what I want requires pleasing those people who are

above me.

People like myself have very little

$.53 \quad 2.75 \quad 1.00$

chance of protecting our personal.

interests when they conflict with

those of people in power.

Even with good ability I will not be given a position of responsibility

$.43 \quad 2.48 \quad 1.00$ without help from powerful others. 
MPI-2: Component,s Four, Five and Six:

Items, Loadings, Means and Standard Deviations

Component Four (Emotional Control)

Items

Loadings $\bar{X}$ S.D.

If someone annoys me I can usually keep

it to myself rather than need to let off

$.54 .3 .45 \quad 1.06$

stearn.

In going places, eating, working, etc., $\quad \begin{array}{ccc}.50 & 2.99 & 1.33\end{array}$ I seem to rush from one thing to

another rather than go about in a calm,

deliberate way.

Are you slow and unhurried in the way $\quad \begin{array}{llll}.58 & 2.69 & 1.08\end{array}$ you move?

I can work carefully on most things $\quad .44 \quad 3.53 \quad 1.00$ without being bothered.

Component Five (Control by Fate). $k=5$

Iteins Loadings $\bar{X}$ S.D.

I think that life is mostly a gamble. $.50 \quad 2.54 \quad 1.06$ $\begin{array}{lllll}\text { To a great extent ny life is controlled } & .43 & 2.18 & .91\end{array}$ by accidental happenings.

I feel that most people could be described $.49 \quad 2.54 \quad .92$ as victims of circumstances beyond their control.

A person cannot really be the master of $\quad .54 \quad 2.50 \quad 1.11$ his fate.

When I get what I want it's usually because I'm lucky.

$.39 \quad 2.34 \quad .85$ 


\section{IABJE in (continued)}

Component Six (Personal Responsibility) $y=3$

Loadings $\bar{X}$ S.D.

There is a direct conncction between how hard I study and the grades I get.

$.43 \quad 3.90 \quad 1.09$

Facing my daily tasks jis a source of $\begin{array}{lll}.57 & 3.35 \quad .79\end{array}$ pleasure and satisfaction.

Good grades in school depends on whether or not the instructor likes $-.44 \quad 1.57 \quad .69$ me. 


\section{TABLES 5}

MPl-2, Reliability Coefficients

Internal and Test-Retest for Components one, T'wo, and Three

Description of coefricient

Coefficient for

Cronbach alpha (Irternal) Comp. 1 Comp. 2 Comp. 3

Test-Retest (External)

$.90 \quad .69 \quad .71$

$.77 \quad .52 \quad .64$


Anxiety and Locus of Control Variabless. Definitions, Dimensionalities and rate of the models

$\therefore$ In the Results section it was shown that the strongest and most stab] a component to emerge in several principal components analyses utilizirg a total sample of 481 subjects corresponds very closely to what cattell called his o factor.

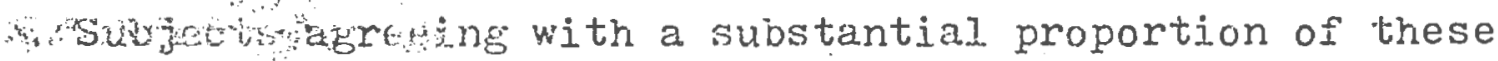
items appear to be reporting a strong preoccupation with feelings of guilt, worry, worthlessness and subjective difficulties. The fact that items from all three sources (Cattell's IPAT anxiety inventory, the TMAS, and Eysenck'S EFI neuroticism inventory) repeatedly loaded on this component would also seem to show that the three instruments are measuring the same thing.

It would also appear that the anxiety variable probably contains two somewhat orthogonal components: the general apprehensiveness and preoccupation with one's self, and concommitant with this, an "ego weakness" or poor self-image component.

Although the other three factors Cattell proposed as being part wi: the anxiety construct (emotional tension, will control, and suspiciousness) did show weak tendencies to emerge as separate components, they do not appear to be strongly related to the first two components mentioned above.

The second variable, internal versus external locus of control, also emerges as a variable in its own right, though not as strongly as the anxiety variable. Subjects responding 


$$
-5^{4}-
$$

to these items appar. to be reportins what Rotter termed a "generalized expectancy" for reinforcenent to be either lareely under their own (internal) control or under the control of fate or powerful others (external control). However, strong support emerges for Levenson's contention that the externality construct contains two distinct components $\therefore$. sortrol by charbe and control by powerful others - and in fact, thase components emerge much more clearly than an interrality component. It is quite possible, contrary to the findings reported by Rotter, that the internal-type statements do draw a "socially desirable" response set. Attention is drawn to the means and standard deviations of the I items which loaded on the second component of the firal PCA. These means are all quite high (3.20 to 4.11 ) and have small standard deviations (as low as .76), indicating a decided restriction in the range of responding toward the high end of the scale. In adaition, the internal-external locus of control variable certainly does not appear to be unidimensional.

The component patterns which emerged in two separate principal components analyses on two separate samples also show good stability, though on the first PCA control by chance was a stronger component and in the second PCA, control by powerful others was the stronger. However, the second PCA, unlike the first, was performed on all the items (anxiety as well as LC) and, as has been shown, the anxiety component absorbed quite a few of the "C"-type items. 
Relationship Detween Anxiety and External Locus of Control

The results - from several directions - strongly support this relatioriship. First, the canonical correlation performed between the 95 items of the anxiety variable and the 60 items of the IC variable resulted in a highly significant canonical correlation between high ego strength and low anxiety on the ore hand, and belief in internal control (and low belier in control by chance) on the other.

In sum, the final instrument that has emerged as the result of tinis research appears to be a fairly stable and reliable measure of two components within the anxiety and $I-E$ constructs, a general tendency to worry and preoccupation, and a belief in contrcl by chance or fate. The items which show significant and stable loadings appear to correspond closely to the theoretical meanings of the two traits of anxiety and perceived locus of control, as discussed in the introduction. In addition, the anxiety and I-E constructs do not seem to be unitary. The anxiety trait appears to have two distinct components, a general tendency toward worry and preoccupation with feelings, and, negatively associated with it, the "ego strength" component. In other words, the tendency to feelings of vague apprehensiveness and worry appears to be strongly associated with an image of one's self as weak and inadequate, a perception that one is unable to cope rationally and effectively with life situations.

The I-E construct also appears to be multidimensional, although, interestingly, the clearest components appear within 
"externality" - ol the individual's perception that he lacks clear and significant control over life situations. The two distinct components which emerge are a belief in control by chance or fate and the attribution of power and control to others.

It also appears that the strongest relationship between anxiety and perceived external control concerns the type of control Leverson has termed "chance or fate".

It nevertheless must be pointed out that although this component pattern appears fairly stable, and the components within it have adequate internal consistencies, the total ariount of variance accounted for remains, practically speaking, quite low. The amount of variance accounted for by the I-E measure ( $35 \%$ in the first PCA when these items were treated separately) does not significantly exceed that obtained by Levenson, using the same Likert-type format. (She accounted for $33 \%$ of the variance.)

Unfortunately, a similar comparison cannot be made with respect to the anxiety scales since typically this information has not been reported for the instruments that were used here as sources for items. 


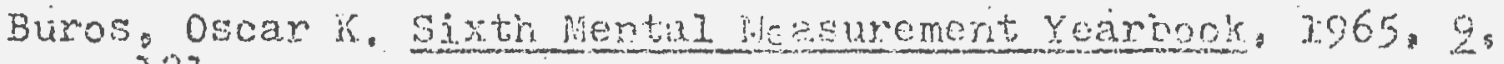
1.22.

Tut,terfield, E.C. Locus of control, test anxiety. and reaction to frustration. I. of personaitity. $1954,22,355-359$.

Cattell, R.B. The Meaning and Measurement of 4 rixiety ard iveuroticism, irew Yorks Konajd, 1961.

dewhom Rersonal Causations the Internal Affective y uniants of Lehavior. Wew Yorks Acidemic Press, 1968.

Eysenck, $M$. Tre Eynamics or Anxiety and Hysteria, Iondons Routledge and Kagan Faul, 1957.

Feather. N.T. Some personality correlates of external control. Australian Joumal of Psychology, 1967, 19, 253-260.

Gurin, P., Gurin G., Jao, R. \& Beattie, M. Internal-external. control. in the motivational dynamics of Negro youth. Jourya] of So:ial Issues, $1969,25(3), 29-53$.

Ioe, V.C. A review of the internal-external control construct. as a pormonality variahie, Psy. Bul1.. 1971. 28. 619.t.40.

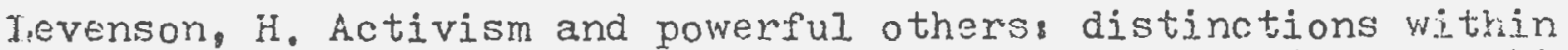
the concept of internal-eyternal control. J. of Perscnality Assessment, $1974,38,377-383$.

Leverson, $H$. Multidimensional locus of control in sociopolitical activists of conservative and liberal ideologies. J. of Personait ty and Social Psychology, 1975, 33, No.2, $3.99-208$.

Iiberty, Burnstein \& Moulton. Concern with mastery. I. of personality, 1966, 34. 105-117.

datarazo, J, D. Wechsler's Measurement and Appraisal of Adul Intelligence, The villiams and Vlilkins Co.. (1972).

Naditch, Gargan \& Wichael. Denial, anxiety, locus of control and the discrepancy between aspirations and achievements as components of depression. J, of Abnormal PSI, 1975. 84. No. 1, 1-9.

Phares, E Locus of Controls A personality Determinant of Behavior, New Jersey, General Learning Press, 1973.

Piaget, J. Understanding Causality, Norton \& Co.. 1974. 
Reynozis, S.I, \& Eurobal, C, A fuctor-andytic study of manifest anxiety and abstract-concrete word recall.

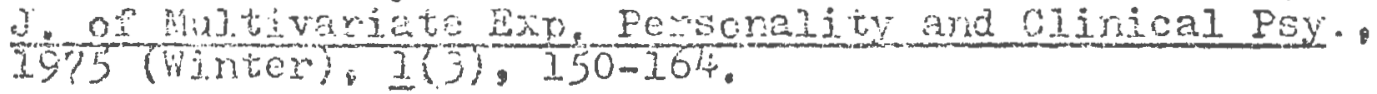

Rotter. J.R. Social ieaming ana Clinical Psychology, Prenticemlati, $195 \%$

Rotter, J.B. Generalized expectancies for internal versus external control of reinforcenert. Esychological Monogravbs: 1965. 80 (Whole No. 609).

Rotter, $\mathcal{J}_{0} B .$, Chance, J.E. \& Phares, E.J. Applications of a Social uearrirg lneory of Personality, Holt, Rinehart c Vinstion, J9\%2.

Rubingtein, J, the Study of Psychology, Dushkin Fublishing Group: $297 \overline{5}$.

Taylor, J.A personality scale of manifest anxiety. $J$. of : Abnorral and Social PSy., 1953, 48. No. 2, 285-290.

Tolor, A. \& Rezniloff, M. Relationship between insight, repression-sensitization, internal-external control, and death anxiety. J, of Abnormal PSy., 1967, 22, 426.4.30。

Watson, D. Relationship between locus of control and anxiety. J. of Personality and Sociai PSY., 1967, 6, 91-92.

White, R.W. Notivation reconsidereds the concept of competence. Psychological Review, 1959, 66, 297-333.

Velicer, W, Item format and inventory structure in the: Eysenck Personality Inventory. University of Rhode 'Island, unpubiished.

Velicer, W, Determining the number of components from the matrix of partial correlations. Psychometrika, 4I, No. 3. September $1976,321-327$. 